\title{
THE PREVALENCE OF INTESTINAL PARASITES IN RAMADI, IRAQ
}

\author{
F. S. Al-Joudi ${ }^{1}$ and A. M. Ghazal ${ }^{2}$ \\ ${ }^{1}$ School of Dental Sciences, University of Science of Malaysia, 16150 Kota Bharu, Malaysia, \\ ${ }^{2}$ Faculty of Pharmacy, Al-Isra Private University, Amman, Jordan
}

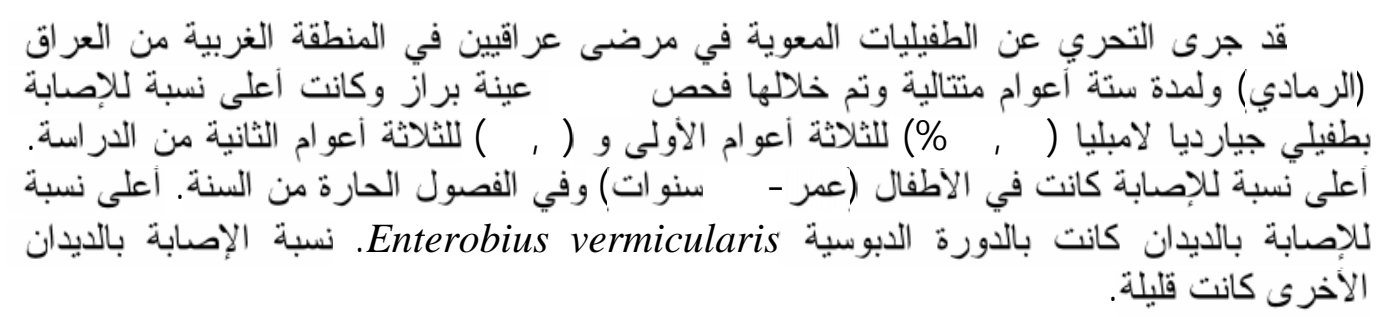

Intestinal parasitic infection was investigated in Ramadi, Iraq, during the period extending from 1992 until 1997. A total number of 6330 cases were included in the study. Giardia lamblia was found to be the most prevalent parasite with an infection rate of $34.50 \%$ in the first period of study (1992-1994) and 56.2\% in the second period of study (1995-1997). Giardiasis had higher incidence during hot seasons. This infection is acquired in early age (110 years).

\section{INTRODUCTION}

Intestinal parasitic infections continue to represent a health problem in many parts of the world. ${ }^{1-4}$ Many factors such as poor hygiene, climate and overcrowding predispose to these infections. The predominant parasites, vary in different geographical areas. Ramadi province is in the western part of Iraq. No study has been done on the prevalence of intestinal parasitic infections in this area, although studies on other areas in Iraq has been performed.

This is a six years retrospective study on a large population to illucidate this health aspect in this region.

\section{PATIENTS AND METHODS}

Most of the patients were referred from clinics to Ibn Sina private medical Laboratory, Ramadi, for a general stool examination. It was part of a routine examination of patients with the exception of a few medical emergency cases (e.g. occult blood)

Samples were examined macroscopically for worms, proglottids or blood and microscopically for parasites. Both direct and concentration methods were used in the study.

Wet mount of each specimen was done by using physiological saline and lugol's iodine solution on microscopic slide.

The Scotch tape technique was used in children whenever suitable to detect eggs or worms of Enterobius vermicularis.

\section{RESULTS AND DISCUSSION}

The study period extended for six years from 1992 until 1997, and has been divided into two consecutive three-year periods, period 1 (1992-1994) and period 2 (1995-1997).

In the first study period, 2810 stool samples were examined, of which 1387 samples had positive findings $(49.36 \%)$ (Table $1)$. In the second period, 3520 sample were examined with 2460 positives $(69.89 \%$ ) (Table 1).

Giardia lamblia was the most frequent intestinal parasites in both periods with an infection rate of $34.44 \%$ in the first period totaling 968 out of 2810 stool sample examined and $56.25 \%$ in the second period totaling 1980 
Table 1: The prevalence of intestinal parasites in patients with different age groups in the two consecutive study period ( period I and period 2).

\begin{tabular}{|c|c|c|c|c|c|c|}
\hline & \multicolumn{3}{|c|}{$\begin{array}{c}\text { Period I, }(1992-94) \\
\text { Total number examined }=2810\end{array}$} & \multicolumn{3}{|c|}{$\begin{array}{c}\text { Period 2, }(1995-97) \\
\text { Total number examined }=3520\end{array}$} \\
\hline & $\begin{array}{c}\text { Number of } \\
\text { positive cases }\end{array}$ & $\begin{array}{c}\% \\
\text { positive }\end{array}$ & $\begin{array}{c}\text { Age } \\
\text { (years) }\end{array}$ & $\begin{array}{c}\text { Number of } \\
\text { positive cases }\end{array}$ & $\%$ age & $\begin{array}{c}\text { Age } \\
\text { (years) }\end{array}$ \\
\hline G. lamblia & 968 & 34.44 & $1-67$ & 1980 & 56.25 & $1-65$ \\
\hline E. histolytica & 227 & 8.08 & $5-63$ & 282 & 8.01 & $4-60$ \\
\hline E. vermicularis & 148 & 5.26 & $2-29$ & 159 & 4.51 & $2-24$ \\
\hline A. lumbricoides & 17 & 0.60 & $5-24$ & 15 & 0.43 & $6-25$ \\
\hline T. trichura & 6 & 0.21 & $8-34$ & 4 & 0.11 & $10-28$ \\
\hline H. nana & 9 & 0.32 & $2-10$ & 6 & 0.17 & $3-20$ \\
\hline T. saginata & 12 & 0.43 & $5-24$ & 14 & 0.40 & $7-15$ \\
\hline $\begin{array}{l}\text { Total number of } \\
\text { positives }\end{array}$ & 1387 & 49.34 & & 2460 & 69.88 & \\
\hline
\end{tabular}

out of 3520 stool sample examined (Table 1). In the first period, G. lamblia made up $69.79 \%$ of all positive cases, totaling 968 out of the 1387 positive cases (Table 1 and Figure 1).

In the second period, giardiasis made up $80.48 \%$ of all positive cases, totaling 1980 out of the 2460 positive cases (Table 1 and Figure 1).

Entamoeba histolytica and Enterobius vermicularis comprised the second most frequent intestinal parasites $(509 \& 307$ cases each). Low incidence of Ascaris lumbricoides, Trichuris trichura, Hymenolepis nana and Taenia saginata infections was noted $(32,10$, $15 \& 26$ cases consequently) (Table 1 and Figure 2).

Higher incidence of infections with Giardia lamblia was noted in the hot seasons of the year (2037 infection) as compared to those in the cold seasons (911 infection) as shown in the Figure 3.

Hot seasons in Ramadi usually extend from April to October.

The sex distribution did not have an influence on the rate of infection (Figure 4).

However, an age-related incidence of giardiasis was established, where a relatively higher frequency of infection was noticed in children and young adults compared to older age groups (Figure 5).

The number of infected children aged between 1 and 10 years was 1442 out of a total 2948, (48.9\%) and 960 patients among those aged 11 to 20 years $(32.5 \%)$.

Giardiasis is prevalent in warm moist climate in many parts of the world. ${ }^{5}$
This finding applies to this region of Iraq (Ramadi) where we found giardiasis as the most prevalent intestinal infection.

These findings are consistent with other studies done in other areas of Iraq ${ }^{6-8}$ while the results disagree with the findings of others. ${ }^{9}$

In other parts of the world where there is different climates the prevalence rates of giardiasis was different. ${ }^{10,11}$

In the summer season there is increase in the fly population. This may contribute to increase in giardiasis incidence we found in our results. Giardiasis is acquired through contaminated food and water. Chlorination of water does not kill Giardia cyst. ${ }^{5}$ Other methods for treatment of water or the use of boiled water for drinking many be recommended.

In endemic areas infection with $G$. lamblia has peak incidence in children. ${ }^{5}$

These findings agree with our results where we found the higher rate of infections in children (1-10 years age). Another common protozoal infection was E. histolytica. The same conditions which predispose to giardiasis also predispose to this infection.

The commonest helminthic infection was Enterobius vermicularis. Transmission of this worm within families may explain this finding. Results of low incidence of infection with other helminths (e.g. Hymenolepis nana, Trichuris trichura \& Taenia saginata) coincide with results of other authors in Iraq. ${ }^{8,9}$ Other important protozoon infection (Cryptosporidium parvum) was not included in this study. Attention should be paid to this parasite in future studies. 


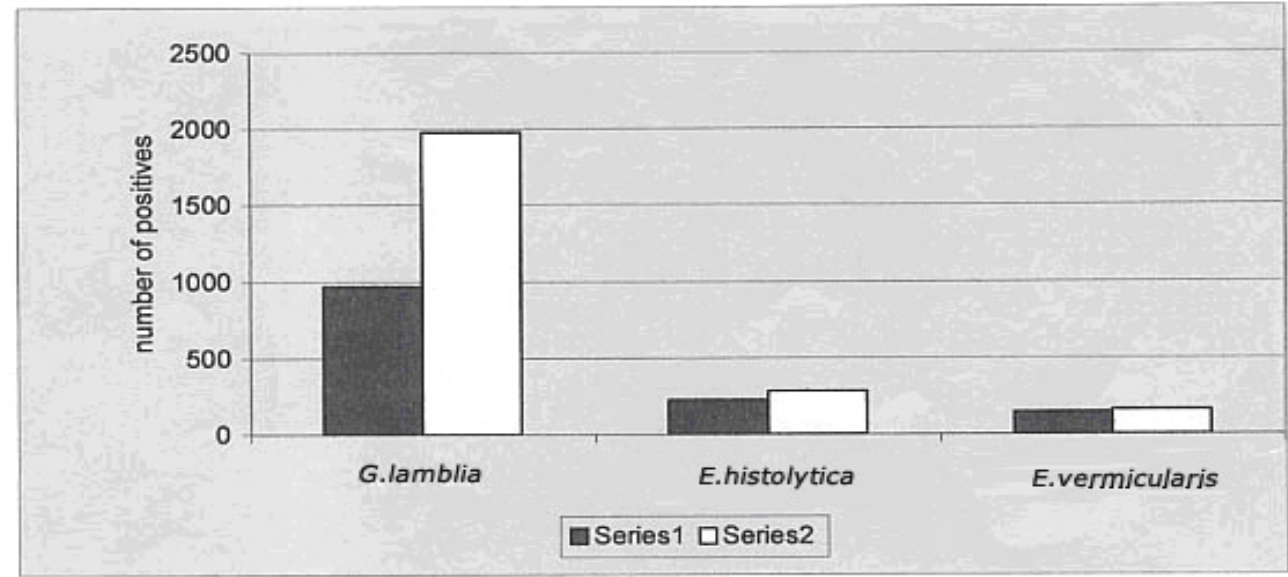

Fig. 1: The numbers of positive findings in stool examinations of the msot frequent intstinal parasites. Series 1 represtns the numbers in the first study period, 1992 to 1994 and series 2 represents the numbers in the second study period, 1995 to 1997.

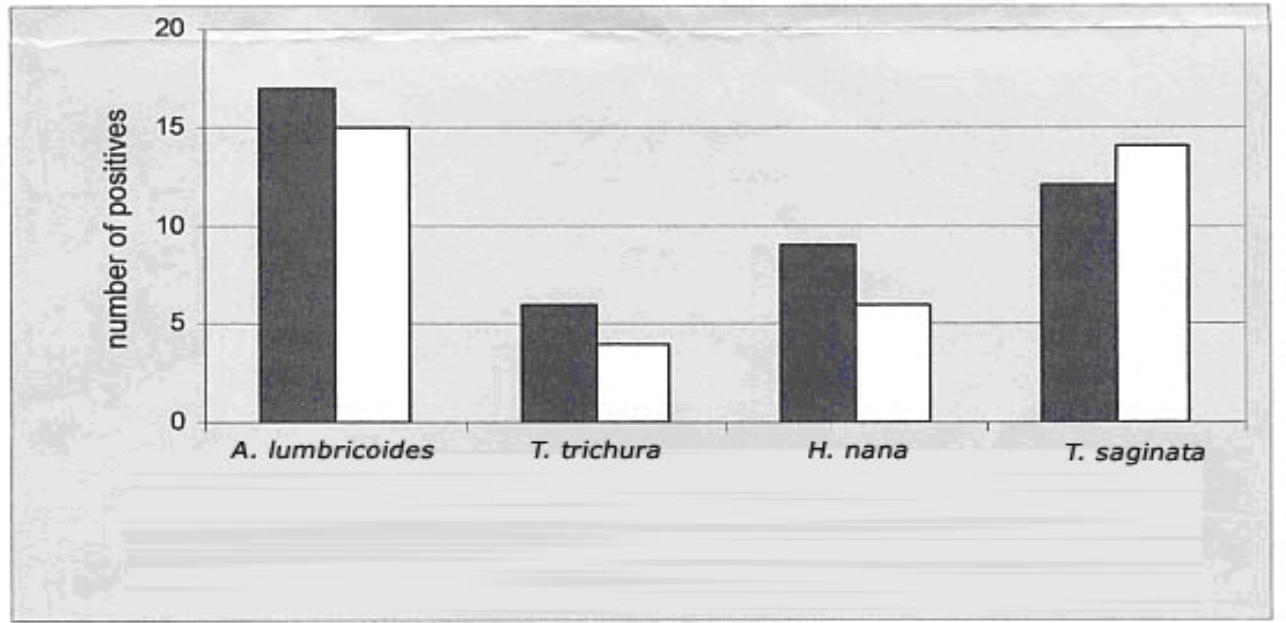

Fig. 2: The numbers of positive findings of the least abundant intestinal parasites. Series 1 represents the first study period, and series 2 represents the second study period. 


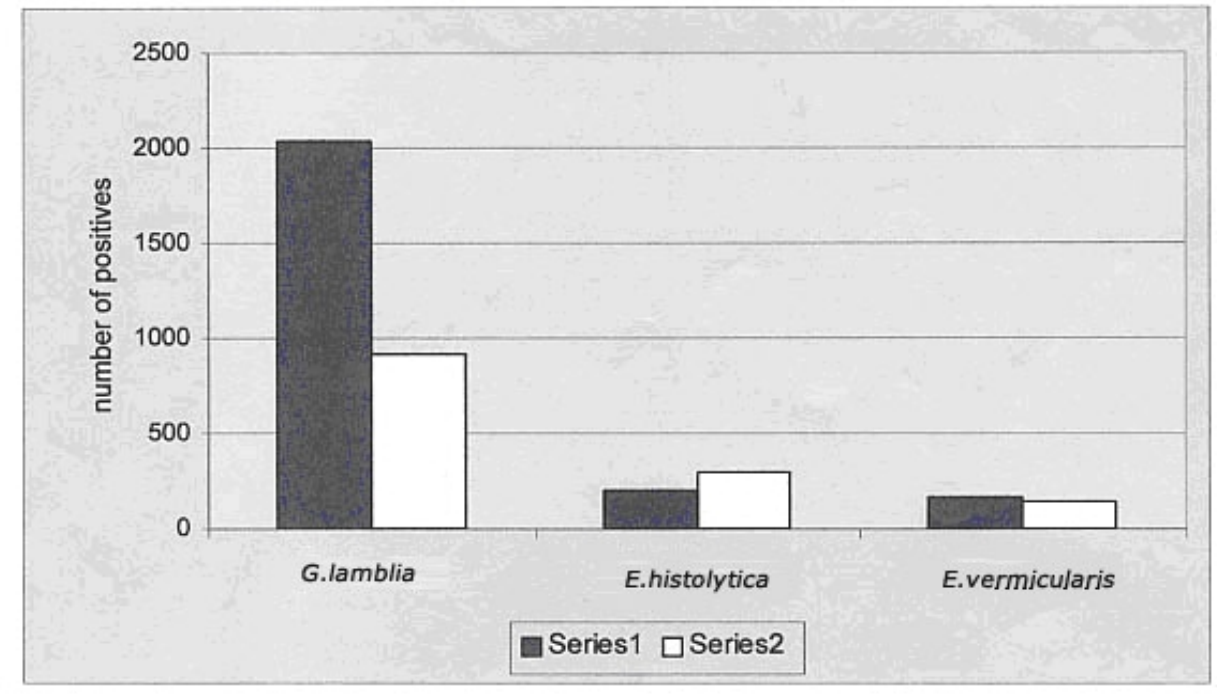

Fig. 3: The seasonal distribution of the three most frequent intestinal parasites. Series 1 represents the hot season, while series 2 represens the cold season.

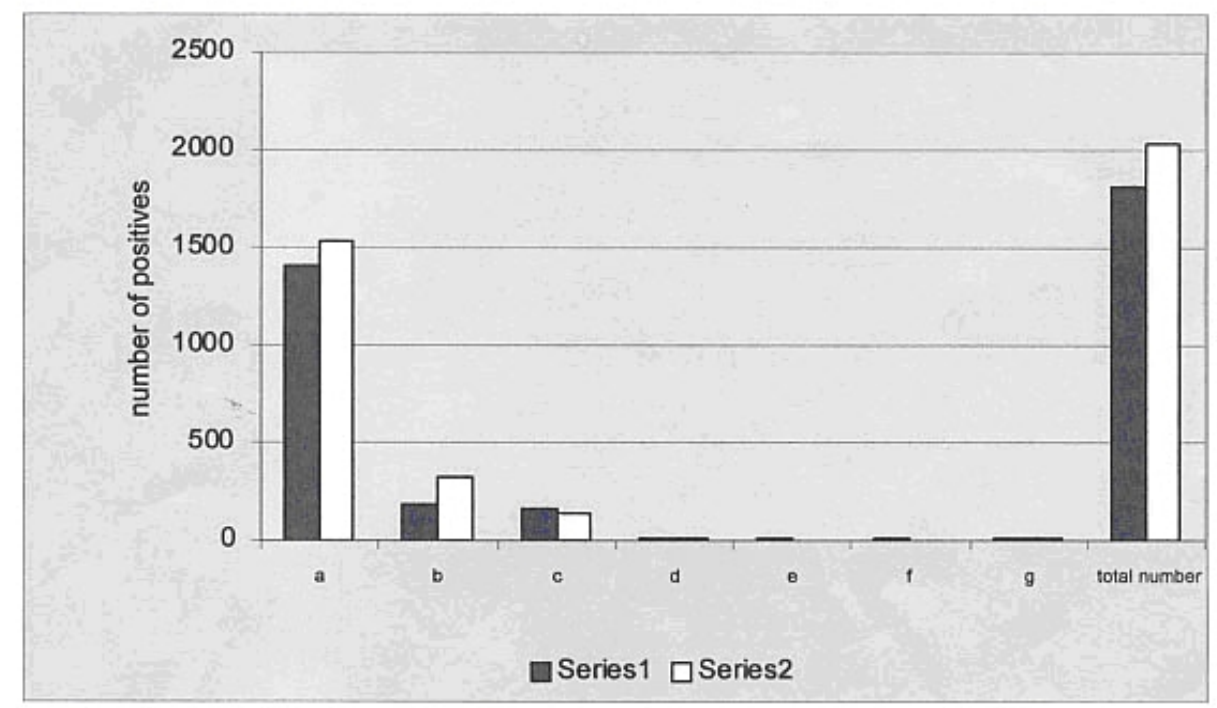

Fig. 4: The sex distribution of all the parasites detected during the study period. Series 1 represents the numbers of female patient and series 2 represents the numbers of male partients. a: G. lamblia; b: E. histolytica; c; E. vermicularis; d: A. lumbricoides; e: T. trichura; f: H. nana; and g: T. saginata. 


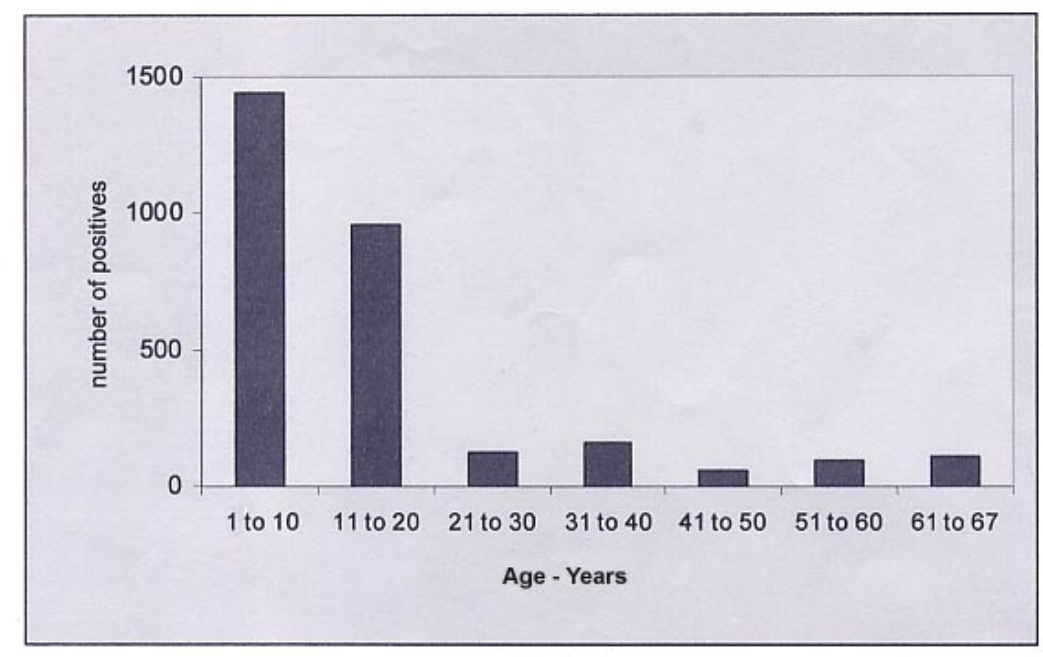

Fig. 5: The incidence of infection with Giardia lamblia according to age, in years, as patients been divided to seven intervals.

\section{REFERENCES}

1- S. Gatti, R. Mahdi, A. Bruno, C. Cevini and M. Scaglia, Ann. Trop. Med. Parasitol., 92, 173 (1998).

2- R. Mercado, J. P. Otto, M. Musleh and M. Perez, Bul. Chil. Parasitol., 52, 36 (1997).

3- R. N. Chunge, P. N. Karumba, N. Nagelkerkes, N. Keleli, M. Wamwea, N. Mutiso, E. O. Andala and S. N. Kinoti, East Afr. Med. J., 68, 112 (1991).

4- O. Faye, N'Diro, M. Ba, O. Gaye, O. Ousman, F. Dieng, T. Bah, I. B. Dieng, Y. Diallo \& S. Diallo, Dakar Med., 43, 104 (1998).

5- P. C. Beaver and R. C. Jung, Animal Agents And Vectors Of Human Disease, $5^{\text {th }}$ Ed. Lea \& febiger, 1985, p. 14.

6- T. I. Al-Jeboori and M. A. Shafiq, J. Fac. Med. Baghdad, 18, 161 (1976).

7- M. A. Al-Dabbagh, A. S. Shaheen, L. A. Zeki and M. Abdullah, ibid., 9, 73 (1967).

8- A. K. Al-Hashimi and S. Al-Najar, ibid., 44, 409 (2002).

9- S. A. Al-Najar, F. A. Mukhlis, S. M. Odisho and R. M. Tahir, ibid., 42, 210 (2000).

10- K. J. Lee, Y. K. Ahn and T. S. Yong, Korean J. Parasitol, 38, 183 (2000).

11- Z. El-Astal, J. Comparative Parasitology, 72, 116 (2005). 